\title{
Lifeworks
}

\section{Multiple diagnoses}

$\mathrm{T}$ his summer, the temporary exhibition spaces at the Ottawa Art Gallery were devoted to three contemporary Canadian artists who have explored the physiological and psychological impact of medical practice and experience. Titled Medical Imprints, the show consisted of individual bodies of work by independent artists with widely divergent viewpoints and approaches.

The largest gallery space housed a retrospective exhibition of the work of the late Theodore Wan, featuring his incisive, darkly witty, pseudo-documentary medical photographs. This exhibition, originally mounted at Dalhousie Art Gallery in Halifax, was recently reviewed in these pages. ${ }^{1}$ The other two spaces housed a collection of installations constructed by Cindy Stelmackowich from medical textbooks and ephemera and a cycle of drawings by Jane Martin of her husband's body after open-heart surgery. Viewed in conjunction, the almost clinical intellectualism of Stelmackowich's conceptually based work and the poignant intimacy of Martin's drawings make for an interesting study in contrasts.

Stelmackowich conjures up the illusion of both an anatomy museum and a medical laboratory in her installations. She places studiously composed displays of medical textbooks, illustrations and paraphernalia such as surgical instruments, test tubes, pipettes and syringes throughout the gallery space. Words and instruments provide the means to performing medical interventions on the body, but are presented in the absence of the human beings who are both subject and object of those interventions. The resulting impression is strangely dehumanizing, and is perhaps calculated to suggest the alienation that patients frequently encounter when they navigate the health care system.

The neutrality with which her displays are presented raises many questions, but also presents a barrier to an understanding of the work. This is per- haps a deliberate reference to frequent communication difficulties between medical practitioners and patients, or an intentional reinforcement of the "mystery" of, or exclusivity of access to, medical knowledge. The 2002 work, Suspending the Laws of Medical Practice, which consists of a wallmounted arrangement of antique test tubes containing strips of words from a medical dictionary floating in a clear solution, can be interpreted in this manner. The words are distorted through the optical effects of the liquid, which on a metaphoric level magnifies their importance and obscures their meaning. Another work, bandbook of SURGERY (2001), is one of several in which medical instruments are actually embedded into the texts. The instruments can be regarded either as conducting knowledge from the text or, on a more sinister level, as impaling or neutralizing the words and their power. In Stelmackowich's displays there are no clear answers or easily discernible points of view. One has to probe deeply to decipher their multiple meanings.

The impact of Martin's work, a collection of tiny pencil drawings called Dear Heart (1998-2000), is very much the opposite. Exhibited in the smallest, most intimate space in the gallery, Dear Heart derives its power from the rawness of its emotional and extremely personal content. Everything brims at the surface here. Initially, the drawings function as documents of the literal imprints of medical practice. They are almost exact recreations of Polaroid snapshots that Martin made of her husband's body as he recovered from major heart surgery in 1995. In both content and scale they remain true to their origins, even to the extent of suggesting not only the bruising and iodine stains on the postoperative body, but also the yellowing of the photographic emulsion with age.

Martin's attention to the details of her husband's body, especially to the interventions and changes it undergoes as he recovers from his surgery, are 


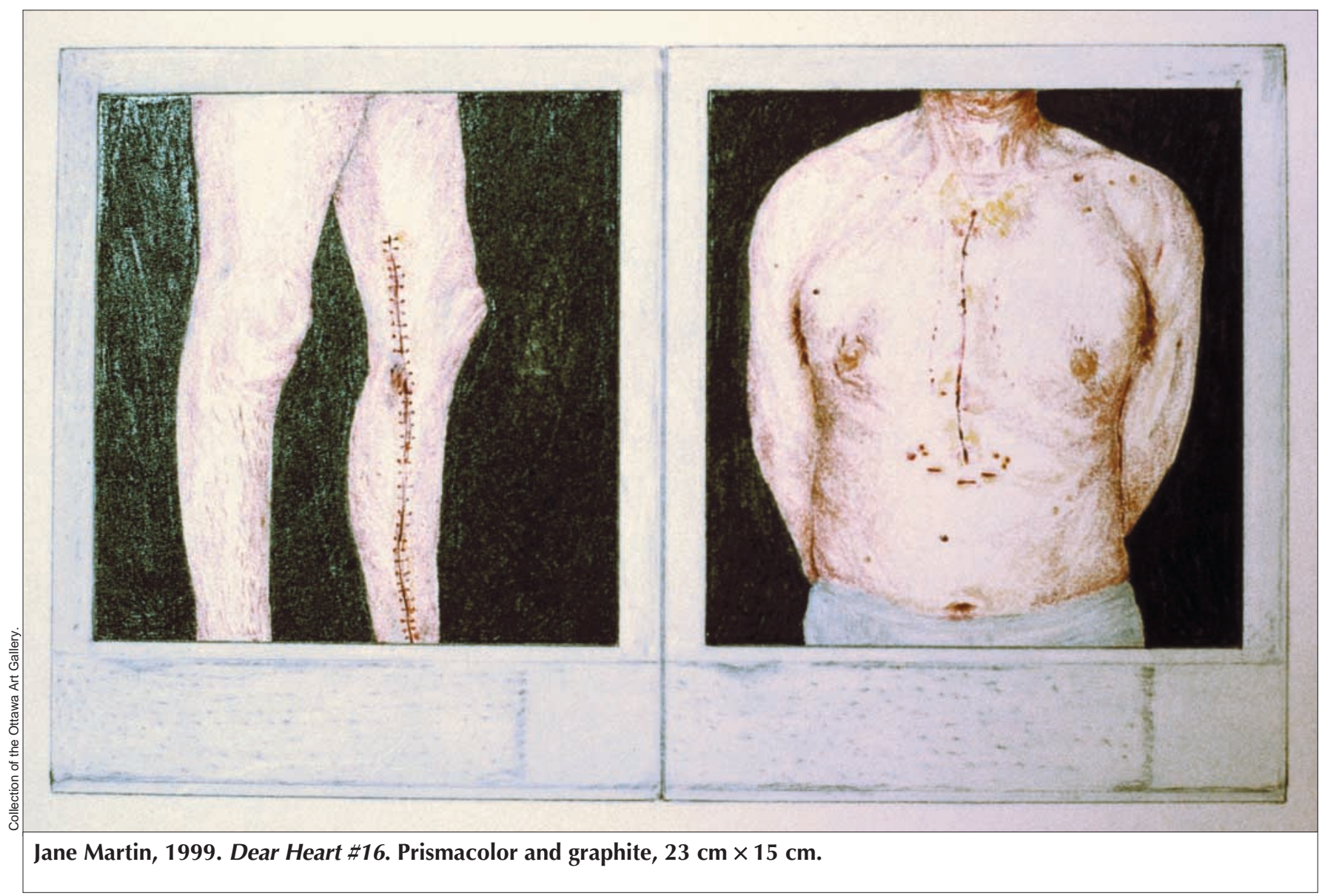

careful and almost obsessive in detail. The bruising, sutures and scars that were formerly so foreign to his body now become its most prominent features. Martin's laborious process of repeatedly drawing and redrawing each line of her husband's body in the many small pictures included in Dear Heart reveals the intensity of her involvement with the actual event and the intimacy of her relationship with her husband. The resulting impression is that the viewer becomes directly engaged in experiencing the artist's act of tracing the length of the scar, at once in awe at its shattering physical presence and at the artist's powerful compulsion to integrate it into the familiar parts of what was once a whole body. The many drawings, and their similarity in appearance, suggest the length and intensity of the grieving process that Martin undergoes as she struggles to acquaint herself with her beloved husband's newly reconfigured body and altered position in the world. In this highly personal context, the viewer suddenly encounters the knowledge of the universality of this experience.

\section{Vivian Tors}

Visual Artist

Ottawa, Ont.

\section{Reference}

1. Flinn S. A mark on his body, a mark on us. CMA7 2004;170:1142-3. 